Article

\title{
Experimental and Numerical Study of Polymer-Retrofitted Masonry Walls under Gas Explosions
}

\author{
Meng Gu ${ }^{1, \dagger}$, Xiaodong Ling ${ }^{1, \dagger}$, Hanxiang Wang ${ }^{2}$, Anfeng $\mathrm{Yu}^{1, * \mathbb{D}}$ and Guoxin Chen ${ }^{1}$ \\ 1 State Key Laboratory of Safety and Control for Chemicals of SINOPEC Qingdao Research Institute of Safety \\ Engineering, Qingdao 266101, China; gum.qday@sinopec.com (M.G.); lingxd.qday@sinopec.com (X.L.); \\ chengx.qday@sinopec.com (G.C.) \\ 2 College of Mechanical and Electronic Engineering, China University of Petroleum (Huadong), \\ Qingdao 266580, China; wanghx1899@163.com \\ * Correspondence: yuaf.qday@sinopec.com; Tel.: +86-0532-8378-6327 \\ + These authors contributed equally to this work.
}

Received: 24 October 2019; Accepted: 14 November 2019; Published: 20 November 2019

\begin{abstract}
Unreinforced masonry walls are extensively used in the petrochemical industry and they are one of the most vulnerable components to blast loads. To investigate the failure modes and improve the blast resistances of masonry walls, four full-scale field tests were conducted using unreinforced and spray-on polyurea-reinforced masonry walls subjected to gas explosions. The results suggested that the primary damage of the unreinforced masonry wall was flexural deformation and the wall collapsed at the latter stage of gas explosion. The presence of polyurea coatings could effectively improve the anti-explosion abilities of masonry walls, prevent wall collapses, and retain the flying fragments, which would reduce the casualties and economic losses caused by petrochemical explosion accidents. The bond between the polymer and masonry wall was critical, and premature debonding resulted in a failure of the coating to exert the maximum energy absorption effect. A numerical model for masonry walls was developed in ANSYS/LS-Dyna and validated with the test data. Parametric studies were conducted to explore the influences of the polyurea-coating thickness and spray pattern on the performances of masonry walls. The polyurea-coating thickness and spray pattern affected the resistance capacities of masonry walls significantly.
\end{abstract}

Keywords: polyurea; gas explosion; masonry wall; field test

\section{Introduction}

Most materials involved in petrochemical plants are flammable and explosive hydrocarbon liquids and gases. Leakage can lead to vapor cloud or gas explosions, which creates a great hazard to existing structures and factory staff. Meanwhile, for historical reasons, unreinforced masonry walls have been extensively used in the petrochemical industry as non-load-bearing components in reinforced-concrete frame buildings, and they are one of the most vulnerable components to blast loads. Most casualties and injuries sustained during external explosions are not caused by the direct effect of the explosion, but rather by the disintegration and fragmentation of a wall, which can be propelled at high velocities by the blast [1]. To reduce the potential hazards to employee safety, it is necessary to study the performances of masonry walls under explosions and find a cost-effective strengthening method.

Due to the potential threats of terrorist attacks and accidental explosions, many researchers have focused on the behaviors and dynamic responses of masonry structures under blast loads. Shi et al. [2] conducted a series of field experiments to investigate the failure mechanisms and fragment characteristics of unreinforced masonry walls. The fragment size distribution was also analyzed, and 
the size distribution of the fine portion of the fragments followed a Weibull distribution. Keys and Clubley [3] carried out two experimental trials using trinitrotoluene (TNT) explosives, which were used to subject nine small masonry structures to blast loading. They described the structural geometry as an array of simple modular panels and proposed a new method to predict the debris distribution produced by masonry structures. Zapata and Weggel [4] conducted a blast test inside a building with conventional walls. Based on the test data, a single degree of freedom (SDOF) model of a masonry wall was established. The SDOF model was able to predict the deflections of the wall quite well if effective input parameters were carefully considered. Solveig et al. [5] employed a full-scale experiment on a three-story reinforced concrete building exposed to an air blast to evaluate their finite element (FE) simulations. They concluded that the FE simulations with solid and structural elements could provide an adequate representation of the global response of the building at minimum computational cost.

The resistance of a masonry wall to blast loads can be enhanced by increasing the equivalent section and ductility of the wall with additional reinforcement materials, including a steel wire mesh, spray-on polyurea, carbon, and glass fiber-composites [6-12]. However, it is important that upgrade costs include not only construction costs but also the potential downtime costs due to the interruption of operations. These costs can increase significantly if the upgrades affect the normal production significantly. The application of stiff materials faces difficulties of high development costs and lack of time-efficient methods for applying the reinforcement to the structure. The masonry wall tests conducted by the Air Force Research Laboratory (AFRL) indicated that the spray-on polymer approach could overcome these issues, and the ability of the material to absorb strain energy was a key factor in the effectiveness toward preventing intrusion of wall fragments into occupant areas [13,14]. A series of impact tests were performed by Wang et al. [15] to investigate the dynamic impact responses of walls strengthened with spray-on polyurea. The test results suggested that the presence of a polyurea layer could transform the collapse of an unreinforced wall into local mortar joint separation and the development of flexure in the walls. The polyurea layer could effectively prevent the collapse and structural failure of the wall and minimize the production of deadly wall fragments. Based on a series of full-scale tests, Moradi [16] developed a single-degree-of-freedom equation to predict the response of membrane-retrofitted concrete masonry walls to impulse pressure loads.

The masonry wall subjected to out-of-plane loads (static, high explosive loads, and gas explosions) were studied by conducting field tests, numerical simulations, and theoretical analysis, as summarized in Table 1. The above-mentioned studies focused on the performances of polymer-retrofitted masonry walls under the blast loads generated by high explosives. Li et al. [17] only investigated the performances of unreinforced masonry walls subjected to vented gas explosions. Studies of spray-on polyurea reinforced masonry walls subjected to gas explosions are very limited in the literature.

Table 1. Summary of previous studies on the masonry wall strengthening. RC: reinforced concrete; CMU: concrete masonry unit; AAC: autoclaved aerated concrete; SDOP: single degree of freedom; AEM: applied element method; CFRP: carbon fiber reinforced polymer; GFRP: glass fiber reinforced polymer

\begin{tabular}{|c|c|c|c|c|c|c|}
\hline Researchers & Year & Structures & $\begin{array}{l}\text { Strengthening } \\
\text { Material }\end{array}$ & Experimental & Numerical & Theoretical \\
\hline Zapata and Weggel [4] & 2008 & Brick walls & - & Explosive & SDOF & \\
\hline Shi et al. [2] & 2016 & Clay brick walls & - & Explosive & & YES \\
\hline Keys and Clubley [3] & 2017 & $\begin{array}{l}\text { London brick } \\
\text { walls }\end{array}$ & - & Explosive & AEM & \\
\hline Li et al. [17] & 2017 & Clay brick walls & - & Gas explosion & LS-DYNA & \\
\hline Solveig et al. [5] & 2018 & $\begin{array}{l}\text { RC walls, Leca } \\
\text { block walls }\end{array}$ & - & Explosive & $\begin{array}{l}\text { ConWep and } \\
\text { LS-DYNA }\end{array}$ & \\
\hline Valluzzi et al. [7] & 2001 & $\begin{array}{l}\text { Brick masonry } \\
\text { vaults }\end{array}$ & GFRP, CFRP & Static & & YES \\
\hline Davidson et al. $[13,14]$ & 2005 & CMU walls & Sprayed-on polymer & Explosive & DYNA3D & \\
\hline Alsayed et al. [8] & 2016 & CMU walls & GFRP & Explosive & AUTODYN & \\
\hline Elsanadedy et al. [9] & 2016 & CMU walls & GFRP & Static & & YES \\
\hline Wang et al. [15] & 2016 & Clay brick, AAC & Sprayed-on polymer & Explosive & & \\
\hline chen et al. [10] & 2019 & AAC panels & $\begin{array}{l}\text { CFRP/sprayed-on } \\
\text { polymer }\end{array}$ & Explosive & & \\
\hline
\end{tabular}


In this study, a series of full-scale field tests on masonry walls subjected to gas explosions were conducted. A simplified micro-model was also developed to predict the dynamic responses of polymer-retrofitted masonry walls using ANSYS/LS-DYNA. The predictions from the numerical simulations were compared with the test data to validate the numerical model. Parametric studies were carried out to evaluate the effects of the polyurea layer thickness and the spraying pattern on the responses of strengthened masonry walls subjected to gas explosions.

\section{Experiments}

A specially designed testing system was prepared for the gas explosion tests. The test system consisted of a pipeline, wall specimens, data-recording instruments, and gas distribution instruments, as shown in Figure 1.

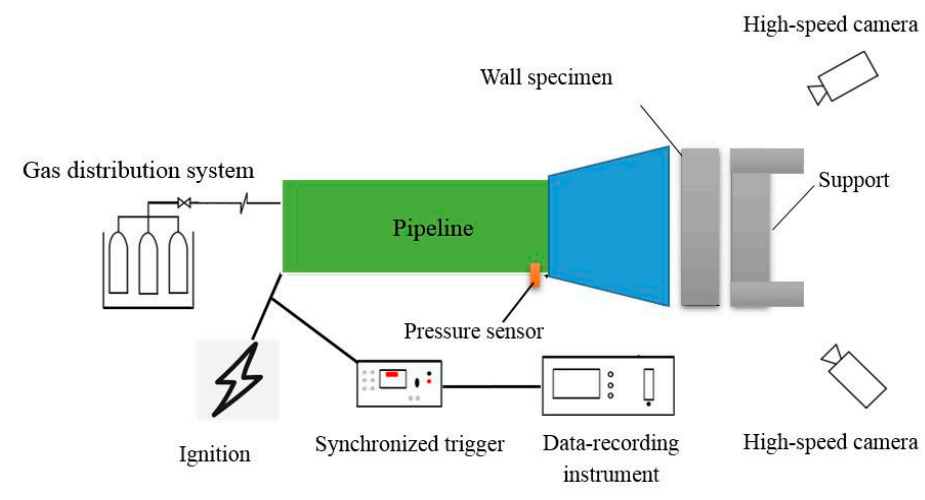

Figure 1. Schematic diagram of the testing setup.

\subsection{Wall Specimens}

One unstrengthened specimen and one rear-face-strengthened specimen were prepared. According to the Chinese standard (GB50003-2011), MU 15 clay bricks and M 5.0 mortar were used for the clay brick walls. The wall specimens with dimensions of $3 \times 2 \times 0.12 \mathrm{~m}$ were lumped with clay blocks with dimensions of $240 \times 115 \times 53 \mathrm{~mm}$ and 10-mm-thick mortar in a "running" pattern, as shown in Figure 2 . Large wall dimensions were selected to avoid scale effects and to reflect the actual performance of a reinforced masonry unit wall under blast loading [15].

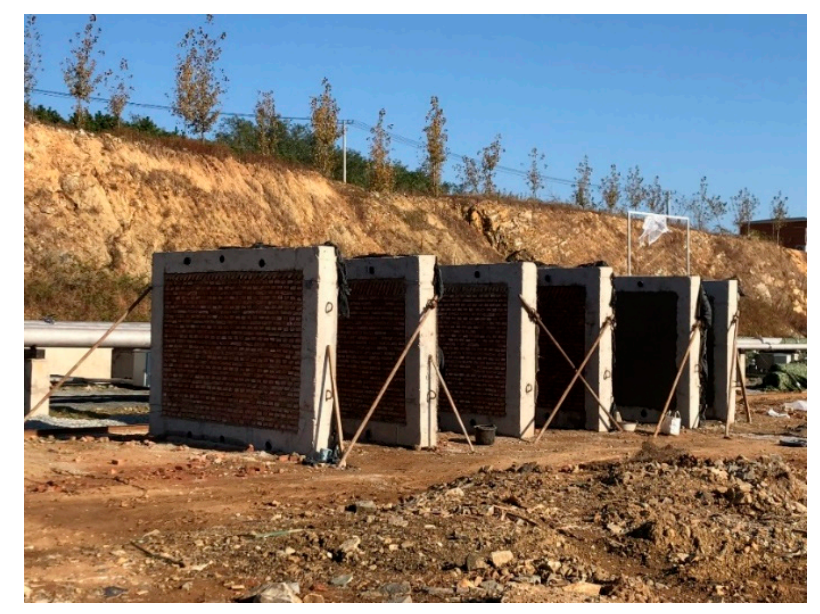

Figure 2. Wall specimens. 


\subsection{Gas Distribution Instruments}

To maximize the explosion overpressure, ethylene with a volume concentration of $5.5 \%$ was chosen as the combustible gas in the tests. The oxygen concentration in the mixture was measured by an oxygen content analyzer, and the ratio of fuel gas to air was adjusted over time to ensure uniform mixing of the flue gas and air.

\subsection{Device Main Body}

The device main body included a pipeline and flaring, as shown in Figures 3 and 4, respectively. The pipeline was used to store gas. Its diameter and length were $500 \mathrm{~mm}$ and $50 \mathrm{~m}$, respectively. To create a more uniform explosion load on the wall surface, the flaring, with dimensions of $2 \times 2 \mathrm{~m}$, was installed at the end of the pipeline.

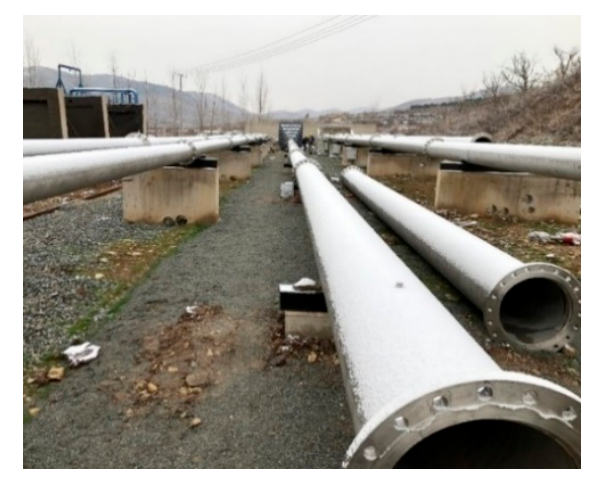

Figure 3. Pipe.

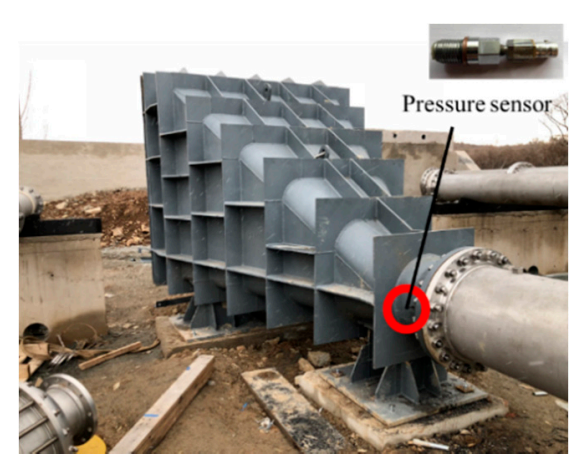

Figure 4. Flaring.

\subsection{Data-Recording Instruments}

The data-measuring system was used to record the explosion overpressure, displacements, and wall failure modes. It was composed of a synchronous trigger instrument, data acquisition instrument, piezoelectric pressure sensors, displacement sensor, and high-speed cameras. The pressure sensors were used to measure the peak overpressure and positive pressure acting time of the explosion shockwaves, as shown in Figure 4. The measurement range was 0-10 MPa. The displacement sensor was used to measure the displacement of the central points of the test walls, as shown in Figure 5, with a measurement range of -5 to $+5 \mathrm{~cm}$. High-speed cameras were arranged on the left and right sides of the test walls to record the failure process of the wall during the test, and the speed of high-speed cameras were 6400 frames. The signals from the pressure sensor and displacement transducers were logged by the data acquisition instrument. 


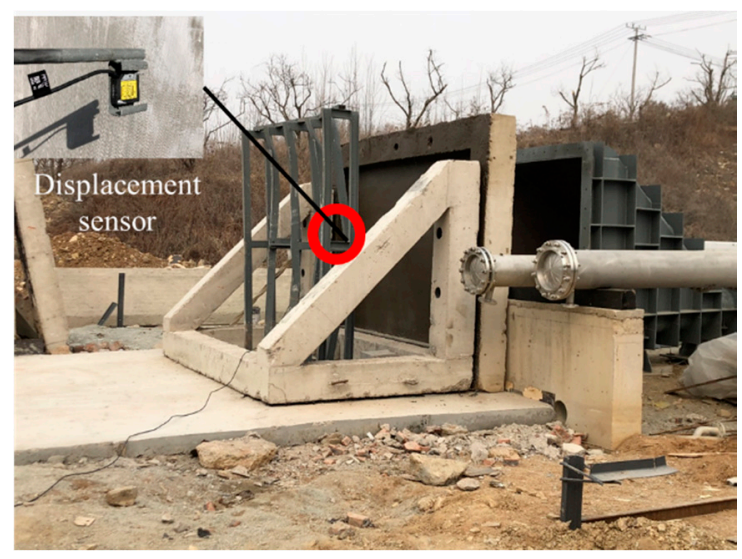

Figure 5. Arrangement of the displacement sensor.

\subsection{Test Procedure}

The supporting structure was designed to fix the test walls on the ground. All the specimens were mounted $1 \mathrm{~m}$ away from the flare. The pressure sensors were installed at the end of the pipeline, and the displacement sensor was arranged at the center of the rear surface of the wall. The spark igniter was installed on the pipe inlet flange, which meant that the igniter was at the edge of the gas cloud. The ignition voltage of spark igniter was $1000 \mathrm{~V}$. The ethylene was pumped from the cylinder gas tank to the pipeline and flaring until the target concentration was reached. Finally, the gas mixture was ignited by a high-voltage power source. The data acquisition system and high-speed cameras were triggered to record data simultaneously.

\section{Testing Results and Discussion}

\subsection{Unreinforced Wall}

Explosion tests of the unreinforced masonry wall were conducted to analyze the failure mode and anti-explosion capacity of the wall. The test results of the masonry wall without an explosion-resistant coating under the first explosion (test 1) are shown in Figure 6. As shown in Figure 6a, large-area concave deformations appeared on the explosion face of the unreinforced wall, and the deformation was almost symmetric. The compression failure of the unstrengthened masonry wall was caused by the high reflected peak pressure. A $\perp$-shaped penetrating crack appeared in the upper half of the wall, as shown in Figure $6 \mathrm{~b}$. The fracture lengths in the horizontal and vertical directions were approximately 1.8 and $1.4 \mathrm{~m}$, respectively, and the widths of cracks were about $25 \mathrm{~mm}$. Bricks almost fell from the central area of the back blasting surface, and cracks developed radially from the center of the wall to the surrounding area. The wall was severely damaged, which indicated that the explosive load was close to the ultimate load-bearing capacity of the unreinforced wall. The blast load time histories were also recorded during the test, and Figure 7 shows that the peak overpressure of the explosive shockwave was about 5.5 MPa. However, no displacement data were obtained due to the mechanical failure. 

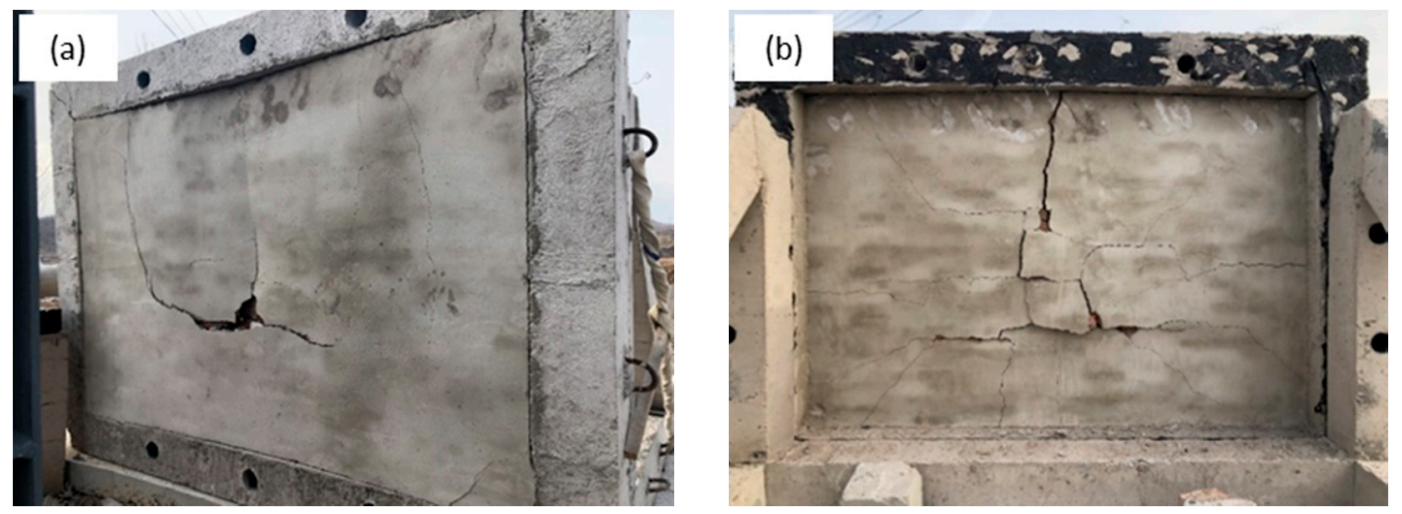

Figure 6. Damage of unstrengthened specimen in test 1. (a) front face and (b) rear face.

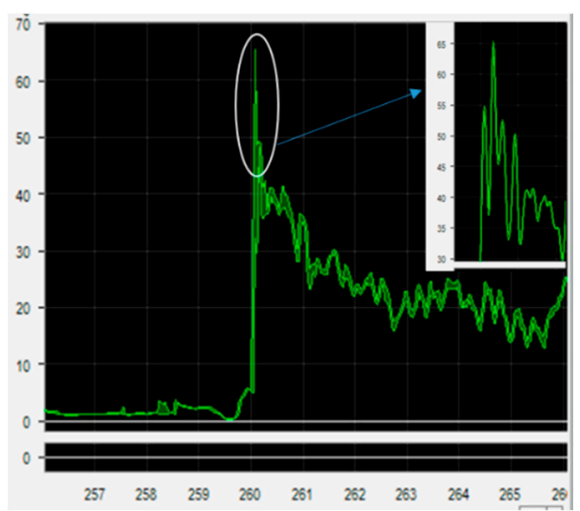

Figure 7. Pressure-time histories in test 1.

To study the distribution of wall debris under explosive loading, subsequent tests were carried out on the wall. The peak overpressure of the explosive shockwave was about $5.2 \mathrm{MPa}$, as shown in Figure 8 . The failure process of the unstrengthened wall specimen during the second explosion (test 2) is shown in Figure 9. Compared with the tests of high explosives in Table 1, the peak pressures from gas explosions were lower but the duration of pressure waves were longer, which lead to different structural responses. Local damages such as spalling or punching damage were more likely to occur when the masonry walls were under close-in TNT explosions as compared to the overall flexural deformations in gas explosions. The test results were similar to those carried out by Li et al. [17], wall specimens experienced damage modes of flexural deformation and a through crack occurred at the middle of the walls. The crack developed with the rise of pressure and the wall specimens collapsed at the latter stage of gas explosion.

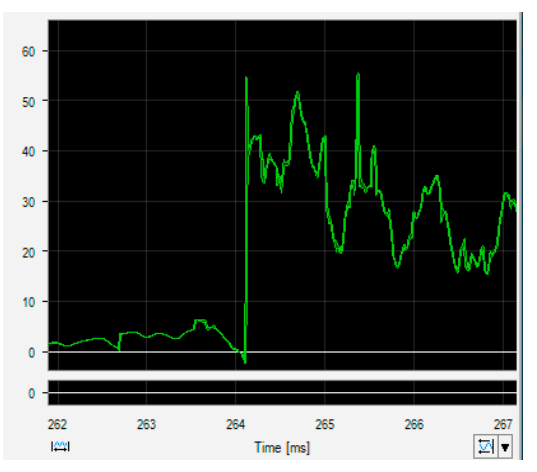

Figure 8. Pressure-time histories in test 2. 

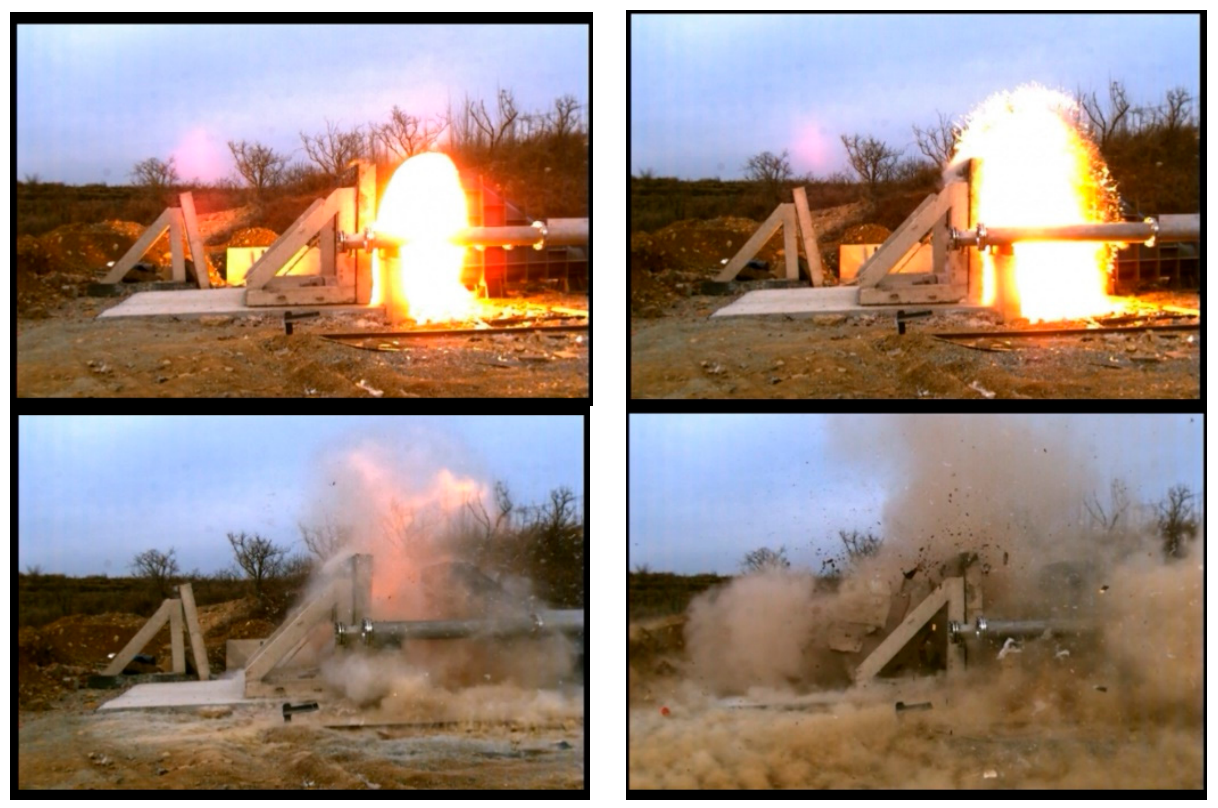

Figure 9. Failure process of unstrengthened wall specimen in test 2.

The fragment distributions of the wall specimen after the gas explosions are shown in Figure 10. The wall collapsed and broke along the bottom, top, and left joints of the frame, with only a 0.4-m-wide wall remaining on the right side. The debris was dispersed in an area of approximately $7.6 \mathrm{~m}$ in length and $5 \mathrm{~m}$ in width. Masonry walls are often used as filling walls of frame structures. The debris produced by a masonry wall under a blast wave can cause severe injuries to indoor personnel.

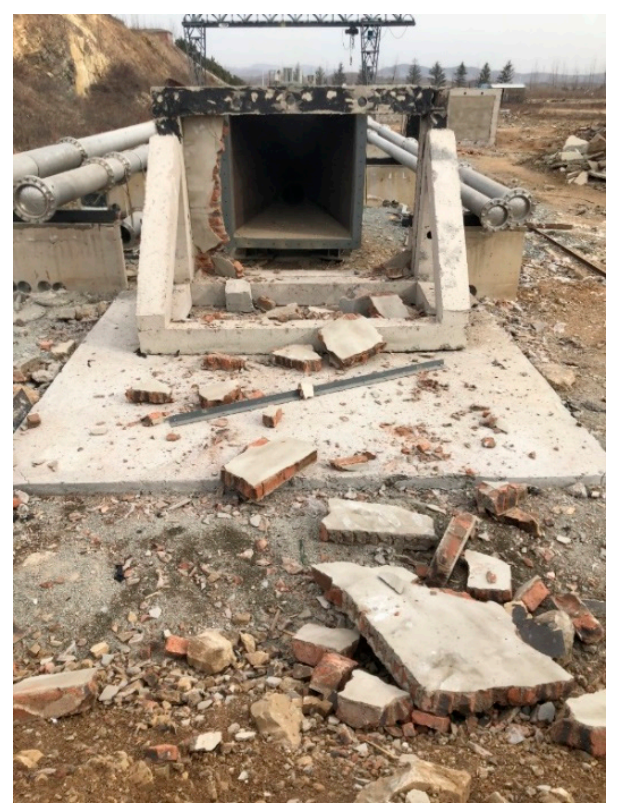

Figure 10. Distribution of debris after the failure of the unstrengthened wall.

\subsection{Polymer-Retrofitted Wall}

Test 3 was carried out to investigate the effectiveness of the polyurea layer and the performance of a polymer-retrofitted wall subjected to gas explosions. The thickness of the polyurea layer on the rear face was $6 \mathrm{~mm}$. The dynamic response of the rear-face-strengthened wall specimen is shown in Figure 11. 

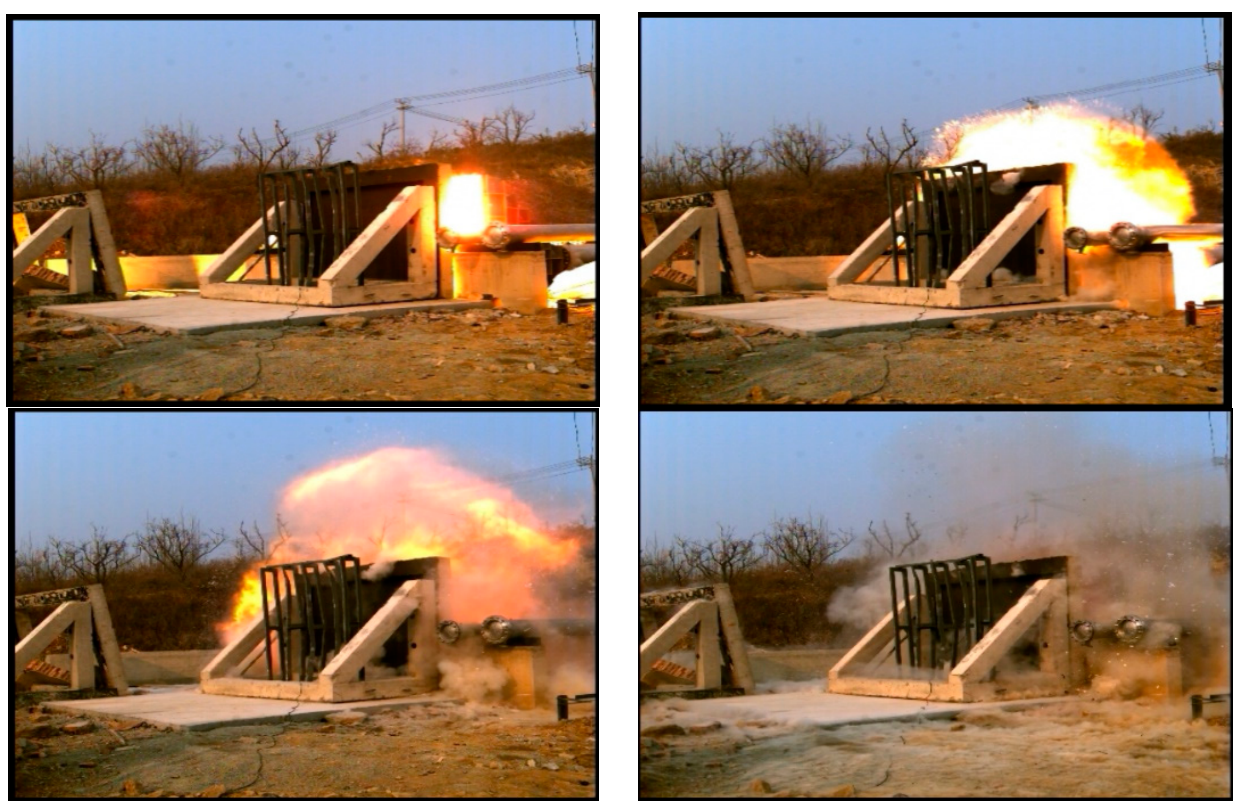

Figure 11. Structural response of rear-face-strengthened wall specimen in test 3.

Figure 12 shows photos of the damage of the rear-face-strengthened wall after the explosion. The wall was concave and deformed slightly, with X-shaped cracks appearing in the central area of the front face. The maximum plastic deformation at the bottom was about $0.06 \mathrm{~m}$. The polyurea coating on the back blasting surface was intact, and no cracks formed. This suggested that the presence of the polyurea layer could effectively improve the blast resistance of the unreinforced wall and reduce the wall failure to local bending deformation.
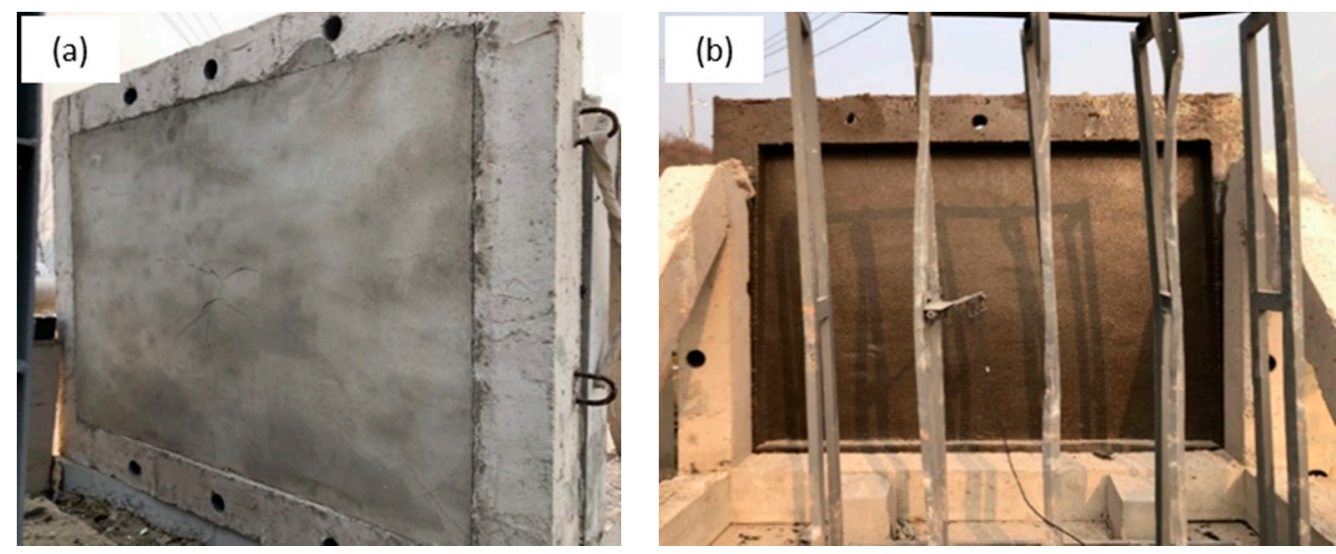

Figure 12. Local damage of rear-face-strengthened specimen in test 3. (a) front face and (b) rear face.

As shown in Figures 13 and 14, the peak overpressure in tests 3 and 4 was 6.0 and $5.5 \mathrm{MPa}$, respectively. The peak pressures in all the tests were basically the same, which indicated that the gas mixture was relatively uniform during each test. Figure 15 shows photographs of the damage to the masonry wall after test 4 . The reinforced brick wall collapsed. However, compared to the unreinforced wall, the traveling distance of the debris was significantly reduced, and the debris was almost completely distributed in the framework of the supporting body. The polyurea coating peeled off along the left, right, and lower edges of the frame. The coatings sprayed on the upper part of the frame were partially torn, whereas the remaining coatings were basically intact. The polyurea layer could absorb the explosive energy, thereby reducing the kinetic energy of the debris and preventing high-speed wall fragments from harming indoor personnel. However, in this test, 
premature debonding of the coating occurred, and the wall failed to produce the maximum effect of the coating. The temperature on the day of coating spraying was $9-12{ }^{\circ} \mathrm{C}$, the wind force level was $4-5$, and the humidity was about $52 \%$. This may have been due to the low temperature of the outdoor spraying operation, causing the coating to not adhere to the frame well. The spraying operation should be carried out under suitable temperature and humidity conditions to improve the adhesion of the coating. Furthermore, steel angle can also be used to reinforce the coating around the frame to maximize the energy absorption effect of the coating. In order to avoid the loss of displacement data during violent explosion, non-contact digital image correlation (DIC) technology can be used to carry out the real-time monitoring of the surface displacement of the wall in future experiments.

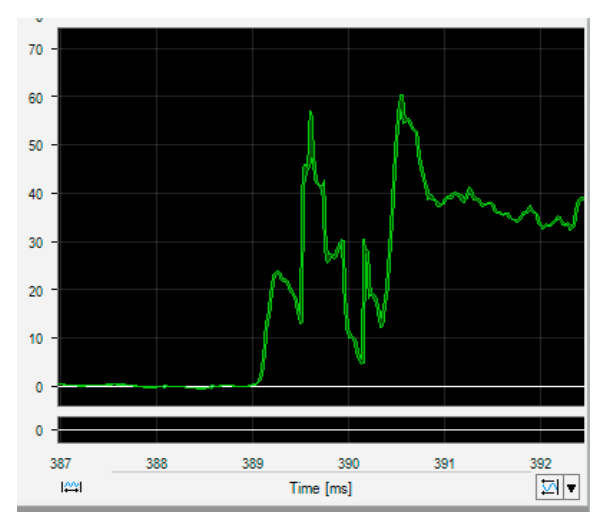

Figure 13. Pressure-time histories in test 3.

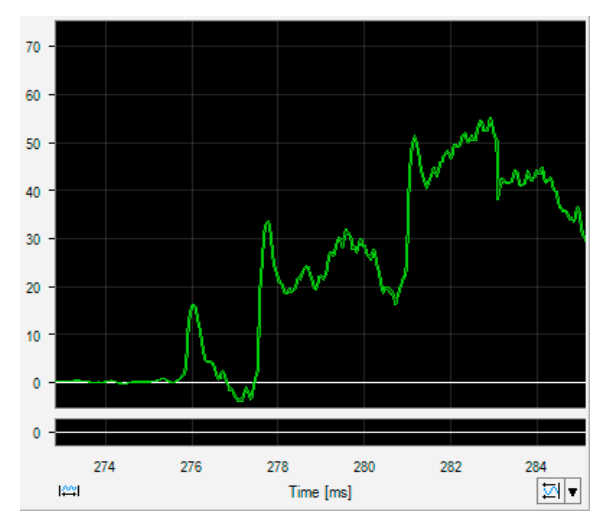

Figure 14. Pressure-time histories in test 4.
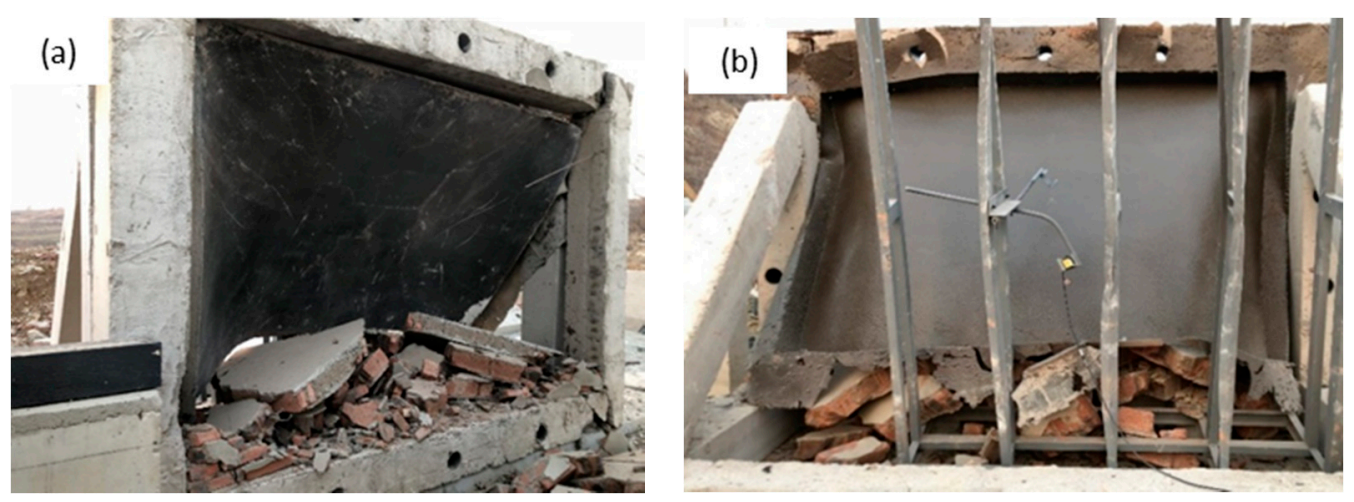

Figure 15. Failure of rear-face-strengthened specimen in test 4 . (a) front face and (b) rear face. 


\section{Numerical Model}

\subsection{Material Parameters}

The anisotropic material model *Mat_96 (MAT BRITTLE DAM-AGE) in LS_DYNA has been used and validated in many studies to model a variety of brittle materials under explosions. Therefore, it was adopted for the clay bricks and mortar in this study. The parameters of the blocks and mortar used in the numerical simulations are listed in Table $2[15,17-20]$. The MAT PIECEWISE LINEAR PLASTICITY material model was used for the polyurea coating. As provided by the supplier, the composite material had a tensile strength of $15.4 \mathrm{MPa}$, breaking elongation ratio of $200 \%$, and tear resistance of $105 \mathrm{~N} / \mathrm{m}$. The mechanical properties of the composite material are summarized in Table 3 [21].

Table 2. Material parameters for brick and mortar.

\begin{tabular}{|c|c|c|c|c|c|c|c|c|}
\hline & $\begin{array}{l}\text { Density } \\
\left(\mathrm{kg} / \mathrm{m}^{3}\right)\end{array}$ & $\begin{array}{l}\text { Young } \\
\text { Modulus } \\
\text { (MPa) }\end{array}$ & $\begin{array}{l}\text { Poisson's } \\
\text { Ratio }\end{array}$ & $\begin{array}{l}\text { Tensile } \\
\text { Strength } \\
\text { (MPa) }\end{array}$ & $\begin{array}{c}\text { Shear } \\
\text { Strength } \\
\text { (MPa) }\end{array}$ & $\begin{array}{l}\text { Compressive } \\
\text { Yield Stress } \\
\text { (MPa) }\end{array}$ & $\begin{array}{c}\text { Fracture } \\
\text { Toughness } \\
(\mathrm{N} / \mathrm{m})\end{array}$ & $\begin{array}{c}\text { Shear } \\
\text { Retention } \\
\text { Factor }\end{array}$ \\
\hline Brick & 1800 & 15,400 & 0.15 & 1 & 0.5 & 19.4 & 120 & 0.03 \\
\hline Mortar & 2100 & 4450 & 0.25 & 0.297 & 0.9 & 8.9 & 140 & 0.03 \\
\hline
\end{tabular}

Table 3. Material parameters of blast-resistant polyurea coating.

\begin{tabular}{cccccc}
\hline $\begin{array}{c}\text { Density } \\
\left(\mathbf{k g} / \mathbf{m}^{3}\right)\end{array}$ & $\begin{array}{c}\text { Elasticity Modulus } \\
\mathbf{( M P a )}\end{array}$ & $\begin{array}{c}\text { Poisson's } \\
\text { Ratio }\end{array}$ & $\begin{array}{c}\text { Tensile Strength } \\
\mathbf{( M P a )}\end{array}$ & $\begin{array}{c}\text { Tear Resistance } \\
\mathbf{( N / m )}\end{array}$ & $\begin{array}{c}\text { Elongation } \\
\mathbf{( \% )}\end{array}$ \\
\hline 1000 & 100 & 0.4 & 15.4 & 105 & 200 \\
\hline
\end{tabular}

\subsection{Geometric Model}

The simplified micro-models for the masonry walls were developed in LS-DYNA, and the mortar, blocks, and polyurea layer were modeled separately. The nodes on their interfaces were merged. The wall model dimensions were a thickness of $120 \mathrm{~mm}$, height of $2 \mathrm{~m}$, and width of $3 \mathrm{~m}$ to match the tests described above, as shown in Figure 2. The sizes of blocks were $240 \times 115 \times 53 \mathrm{~mm}$, and the thicknesses of the mortar and polyurea layer were 10 and $6 \mathrm{~mm}$, respectively, identical to the thicknesses in the test specimens. The three-dimensional solid element SOLID164 was used to discretize the geometrical model. Considering the computational accuracy and efficiency, the combination of a 20-mm mesh size for the blocks and one layer for the mortar joint and polyurea coating was adopted for the numerical model.

\subsection{Numerical Model Calibration}

In the tests, the pressure sensor was located at the end of the pipeline. To obtain the explosion overpressure value at the wall, after the tests, a pressure sensor with a range of $0-1 \mathrm{MPa}$ was also arranged at a distance of $1 \mathrm{~m}$ from the flaring. The sensor was destroyed in the first measurement and reached the maximum range in the second measurement, but it was not destroyed. According to the information provided by the supplier, the damage pressure of the sensor was $2 \mathrm{MPa}$, and the positive-pressure-action time measured by the sensor at the end of the pipeline was about $2 \mathrm{~ms}$. These were used as the explosion loads in the numerical simulations.

Figure 16 shows the comparison between the numerical simulation and the experimental results of the unreinforced masonry wall in test 1 . A large depression area and deformation appeared on the face of the explosion. The numerical simulation predicted depressions caused by the blast wave, as shown in Figure 16a. The destruction area of the front surface of the wall was basically symmetric, and the edge of the area was arc shaped. A $\perp$-shaped crack penetrated the wall in the test. The calculation results showed that the same main crack penetrated to the back of the masonry wall, as illustrated in Figure $16 \mathrm{~b}$, and the brick in the center of the wall almost fell out. The fracture lengths in the horizontal 
and vertical directions were 1.78 and $1.5 \mathrm{~m}$, respectively, and the widths of cracks were about $23 \mathrm{~mm}$. The values of the three parameters in the test were $1.8 \mathrm{~m}, 1.4 \mathrm{~m}$, and $25 \mathrm{~mm}$ respectively. The results of the simulation are basically consistent with the experimental data.

(a)

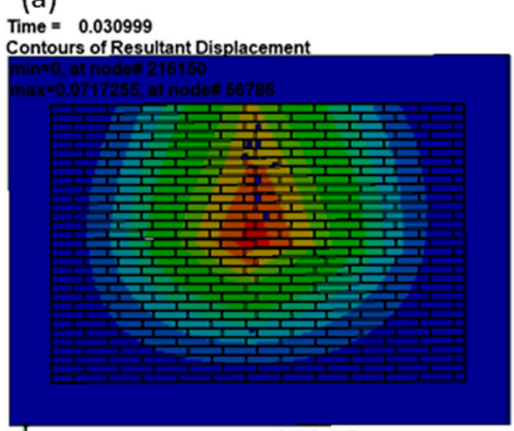

Fringe Levels 7.173e-02 6.455e-02 $5.738 \mathrm{e}-02$ 5.021e-02 4.304e- 02 $3.586 \mathrm{e}-02$ $2.869 \mathrm{e}-02$ $2.152 \mathrm{e}-02$ $1.435 \mathrm{e}-02$ $7.173 \mathrm{e}-03$ $0.000 \mathrm{e}+00$ _ (b)

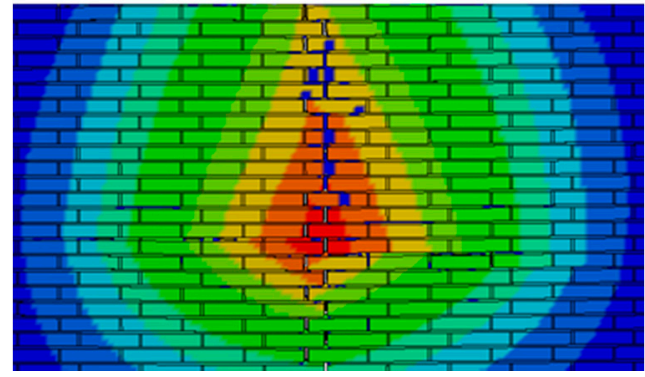

Figure 16. Failure pattern predictions of unreinforced specimen under the first explosion. (a) front face and $(\mathbf{b})$ rear face.

Figure 17 shows the numerical simulation results of the polymer-retrofitted masonry wall in test 3. In Figure 17a, the deformation area of the central area of the wall was approximately $0.12 \mathrm{~m}^{2}$, and the numerical simulation predicted a value of approximately $0.14 \mathrm{~m}^{2}$. In Figure $17 \mathrm{~b}$, the coating on the back burst surface remained intact, and the calculated results showed that the coating was also intact, with slight arching in the center of the coating. Therefore, the numerical model developed in this study yielded acceptable predictions and could be used to predict the performances of polymer-retrofitted masonry walls against gas explosions.

(a)

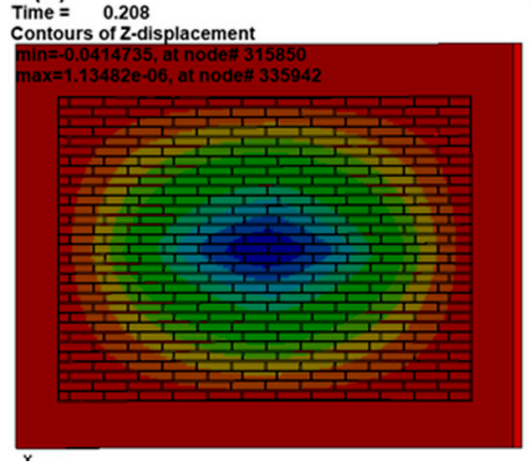

(b)

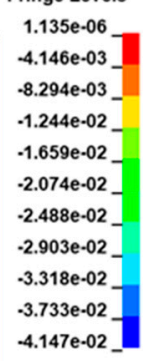

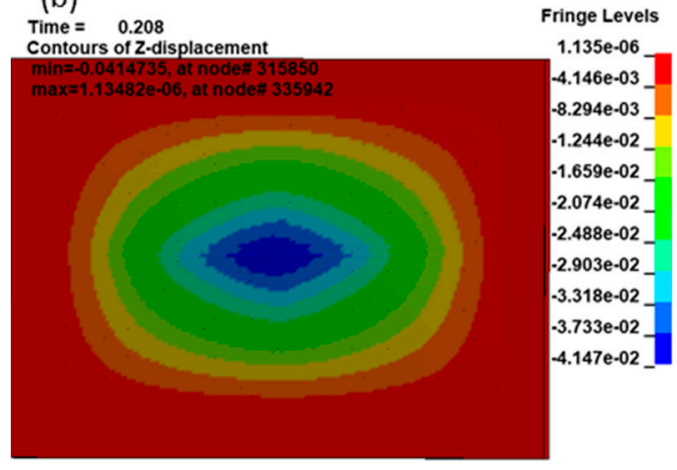

Figure 17. Failure pattern predictions of polymer-retrofitted wall under the first explosion. (a) front face and (b) rear face.

\section{Numerical Simulations}

The masonry walls of petrochemical buildings are larger than the specimens used in this study, and most are $240 \mathrm{~mm}$ thick. Therefore, based on the calibrated models, numerical models with dimensions of $4 \mathrm{~m} \times 3 \mathrm{~m} \times 240 \mathrm{~mm}$ were established according to the pattern shown in Figure 18. In the simulation calculations, the peak overpressure was $69 \mathrm{kPa}$, and the positive-pressure time was $20 \mathrm{~ms}$ [22,23]. 


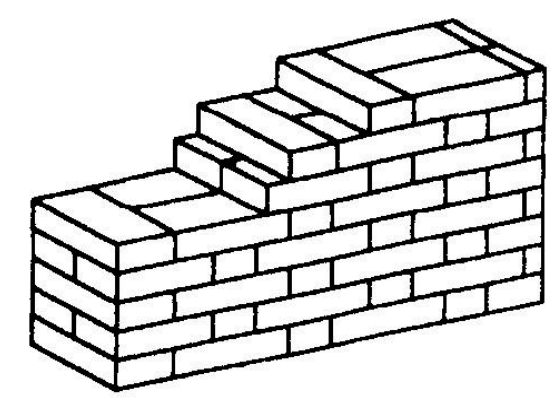

Figure 18. Wall with 240-mm thickness.

According to the Chinese standard (GB50779-2012) [22], the peak reflected pressure can be calculated as follows:

$$
P_{r}=\left(2+0.0073 P_{s o}\right) P_{s o},
$$

where $P_{r}$ is the peak reflected pressure $(\mathrm{kPa})$. The stagnation pressure can be expressed as

$$
P_{s}=P_{s o}+C_{d} q_{o}
$$

where $P_{s}$ is the stagnation pressure $(\mathrm{kPa})$, and $\mathrm{C}_{\mathrm{d}}$ is the drag coefficient. The drag coefficient depends on the shape and orientation of the obstructing surface. For a rectangular building, the drag coefficient may be taken as +1.0 for the front wall and -0.4 for the side and rear walls and the roof.

The duration of the equivalent triangle was calculated as follows:

$$
\begin{gathered}
t_{c}=3 S / U<t_{d} \\
t_{e}=2 I_{w} / P_{r}=\left(t_{d}-t_{c}\right) P_{s} / P_{r}+t_{c} \\
I_{w}=0.5\left(P_{r}-P_{s}\right) t_{c}+0.5 P_{s} t_{d}
\end{gathered}
$$

where $I_{\mathrm{W}}$ is the positive pressure impulse, $S$ is the clearing distance, which is the smaller of $\mathrm{H}$ or $\mathrm{B} / 2(\mathrm{~m})$, $t_{e}$ is the duration of the equivalent triangle $(\mathrm{s})$, and $t_{c}$ is the duration of the reflected overpressure effect (s). The calculated front wall loading is shown in Figure 19.

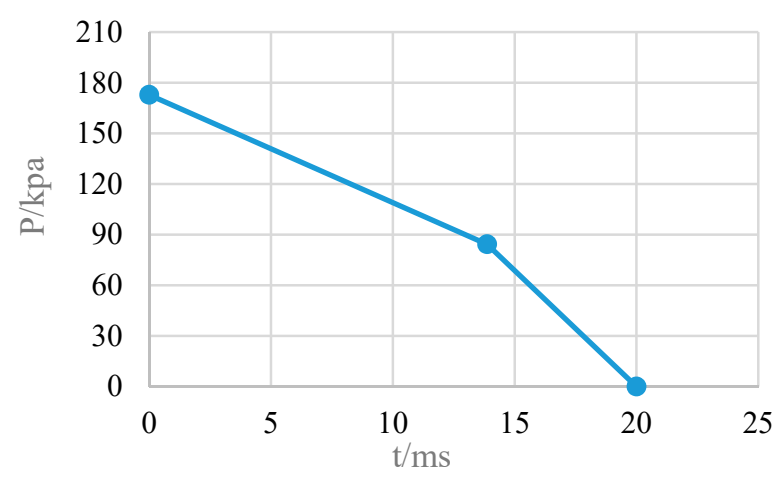

Figure 19. Wall loading.

\subsection{Unreinforced Wall}

Figure 20 shows the structural response of an unsprayed wall. According to the figure, the brick wall collapsed. Selecting the center point of the wall as the observation point, the displacement curve is shown in Figure 21. In the range of $0-0.2 \mathrm{~s}$, the displacement tended to increase significantly, and the maximum displacement was $0.7 \mathrm{~m}$, which was larger than the thickness of the clay brick wall. The velocity curve is shown in Figure 22. As shown in the figure, the wall velocity increased first, after which it remained basically constant, reaching a maximum velocity of $3.84 \mathrm{~m} / \mathrm{s}$ at $0.028 \mathrm{~s}$. 

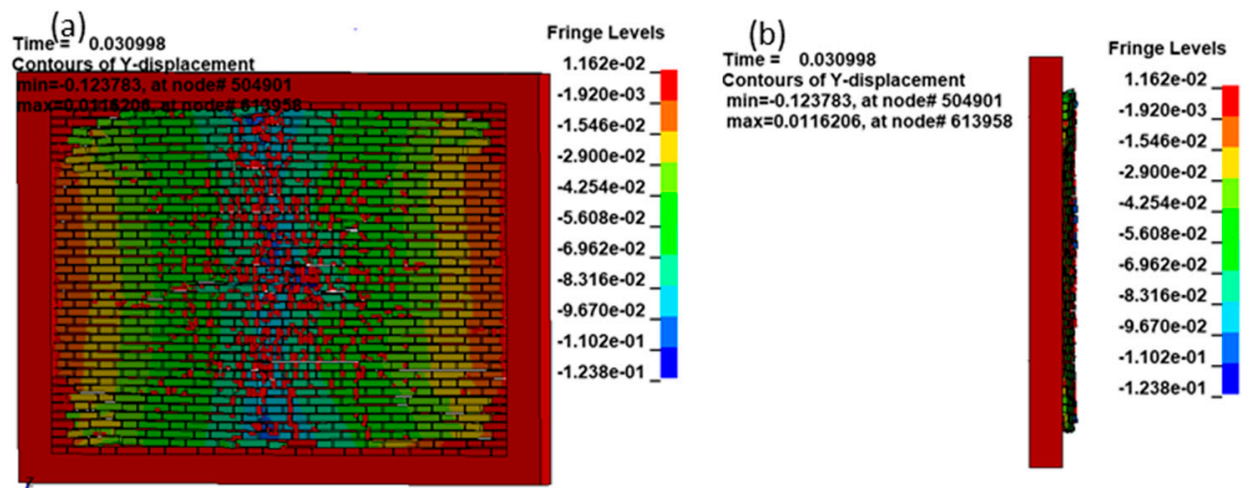

Figure 20. Structural response of the clay brick wall without sprayed blast-resistance coating. (a) front view and (b) side view.

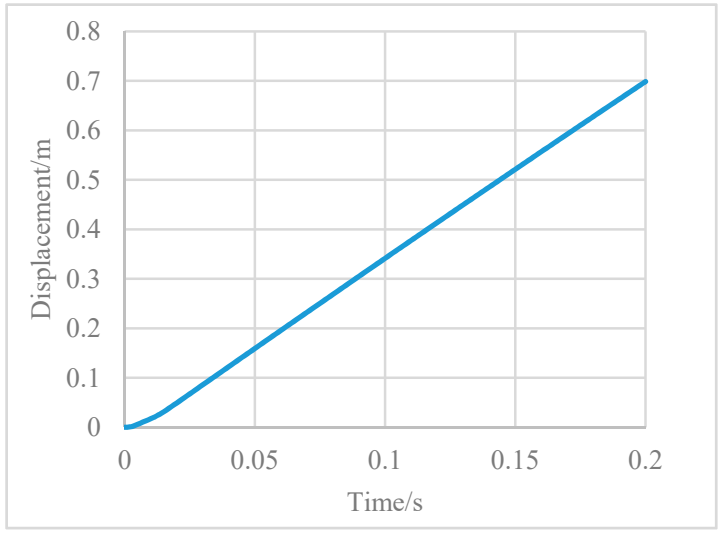

Figure 21. Displacement-time history curve of the unreinforced wall.

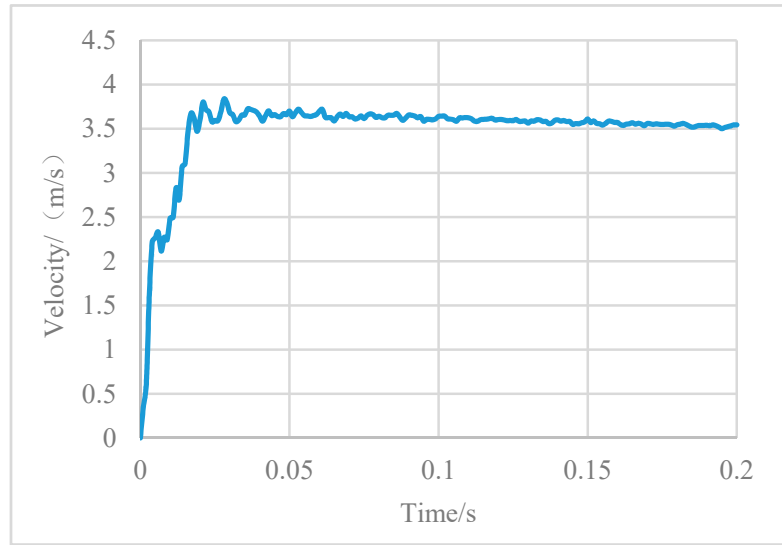

Figure 22. Velocity-time history curve of the unreinforced wall.

\subsection{Coating Thickness}

Masonry walls strengthened at the rear face with layer thicknesses of 3,6, and $8 \mathrm{~mm}$ were considered. Figure 23 shows the response of the strengthened wall with a 6-mm coating. The mortar and bricks were damaged by the blast loading, but the coating remained intact and effectively reduced the formation of wall debris.

The displacement histories at the centers of masonry walls are shown in Figure 24. The notation $0-3,0-6$, and 0-8 represent the polyurea coatings with corresponding thickness ( $\mathrm{mm}$ ) sprayed on the rear surface of clay brick wall and no coating on the front surface. The displacement of all the reinforced walls increased first and subsequently decreased gradually. The maximum displacements 
of the $0-3,0-6$, and $0-8$ walls were $0.29,0.21$, and $0.19 \mathrm{~m}$, respectively. With the increase in the coating thickness, the maximum displacement of wall decreased, which indicated that the anti-explosion ability was significantly improved. The kinetic and internal energies of the coatings are shown in Figures 25 and 26, respectively. The internal energy absorbed by the coating was much greater than the kinetic energy. With the increase in the coating thickness, the amount of wall deformation decreased, the internal energy of the coating decreased, and the wall absorbed more explosive energy through the destruction of the mortar or brick.
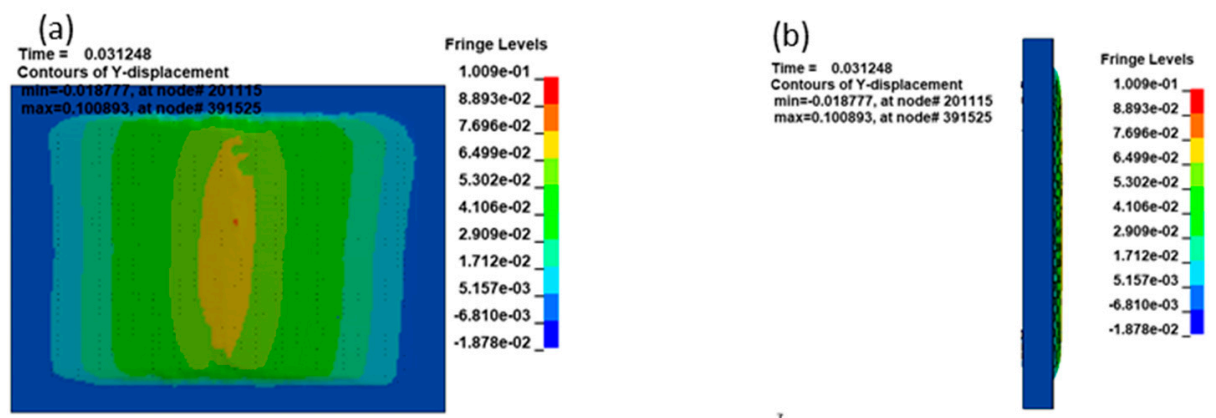

Figure 23. Structural response of the 0-6 clay brick wall. (a) front view and (b) side view.

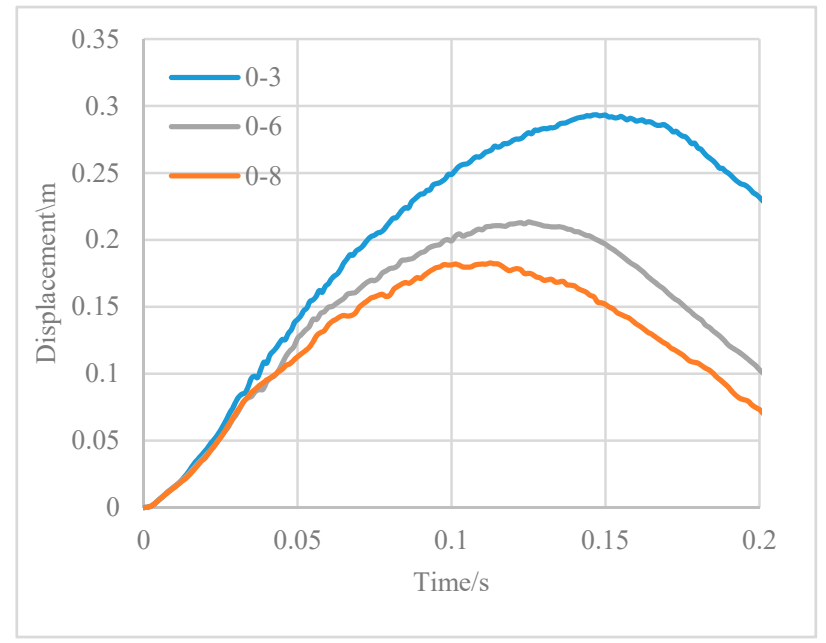

Figure 24. Displacements of walls strengthened with different coating thicknesses.

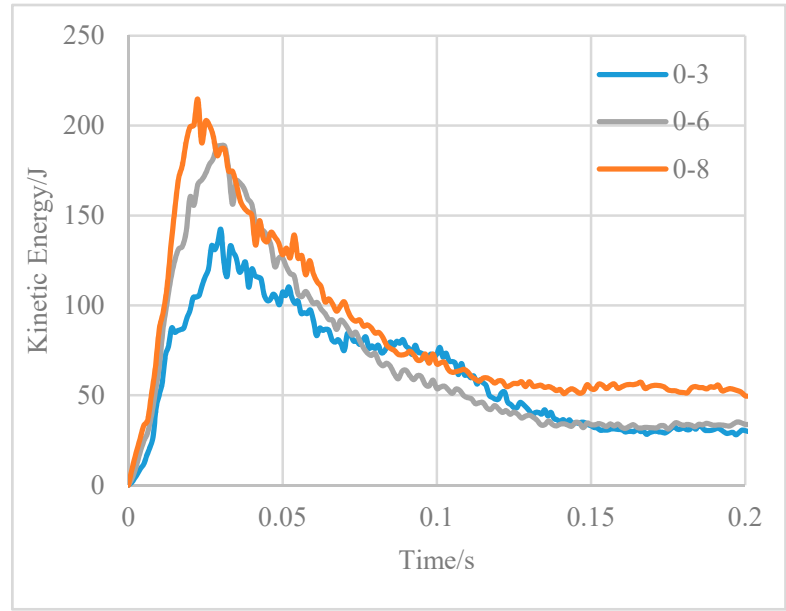

Figure 25. Kinetic energies of coatings with different thicknesses. 


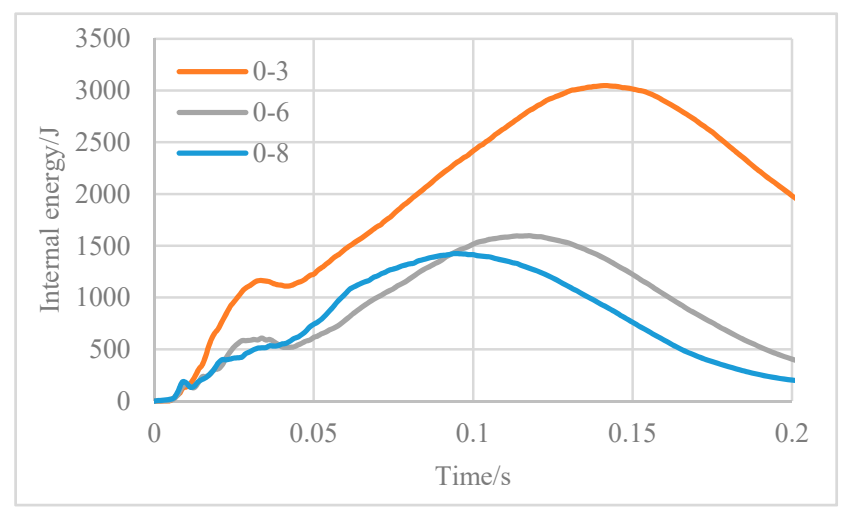

Figure 26. Internal energies of coatings with different thicknesses.

\subsection{Spray Pattern}

To study the effect of the spraying method on the explosion resistance of the reinforced walls, 3 -mm-thick explosion resistant coatings were sprayed on the front (3-0), back (0-3), and both sides of the clay brick walls (3-3).

The coatings of the walls strengthened using three different spray patterns were not damaged under explosive loading. The side views of the reinforced walls are shown in Figure 27. When the polyurea was sprayed only on the front face of the masonry wall, debris was launched from the back of the wall.

The displacement curves of the different spraying methods are shown in Figure 28. The maximum displacements of the $3-0,0-3$, and 3-3 walls were $0.55,0.29$, and $0.11 \mathrm{~m}$, respectively. This suggested that the masonry wall with the double-side reinforcement exhibited the best explosion resistance. For the 3-3 wall, the thickness of the coating on the front side was the same as that on the back side. The kinetic and internal energies of the coating on the front side were larger than the corresponding values of the back side, as illustrated in Figures 29 and 30, which showed that the energy absorption effect of the front face coating was better than that of the back face coating.
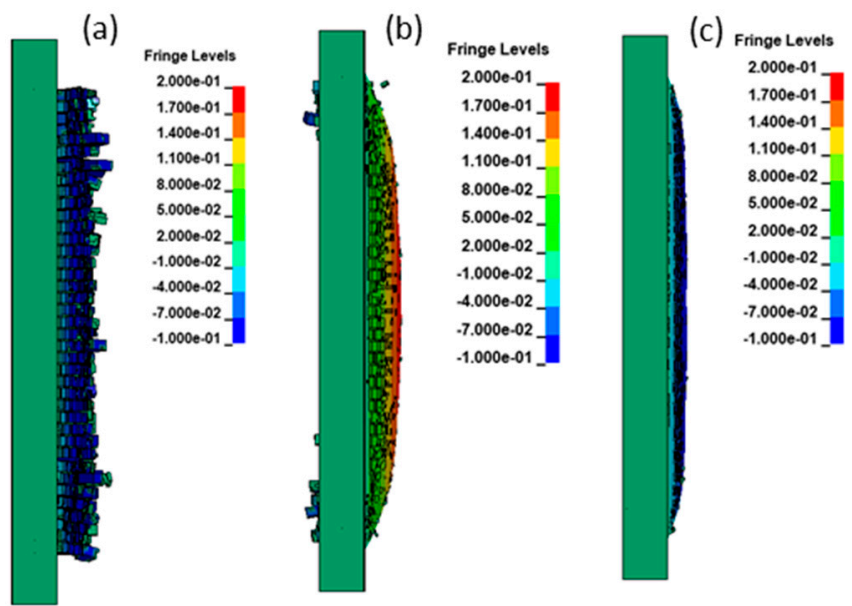

Figure 27. Structural responses of clay brick walls (0.07 s). (a) 3-0, (b) $0-3$ and (c) 3-3. 


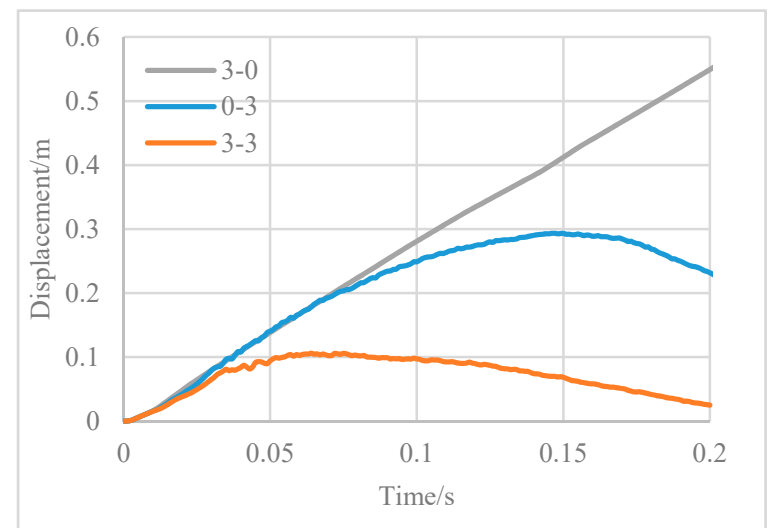

Figure 28. Displacements of walls strengthened with different spraying patterns.

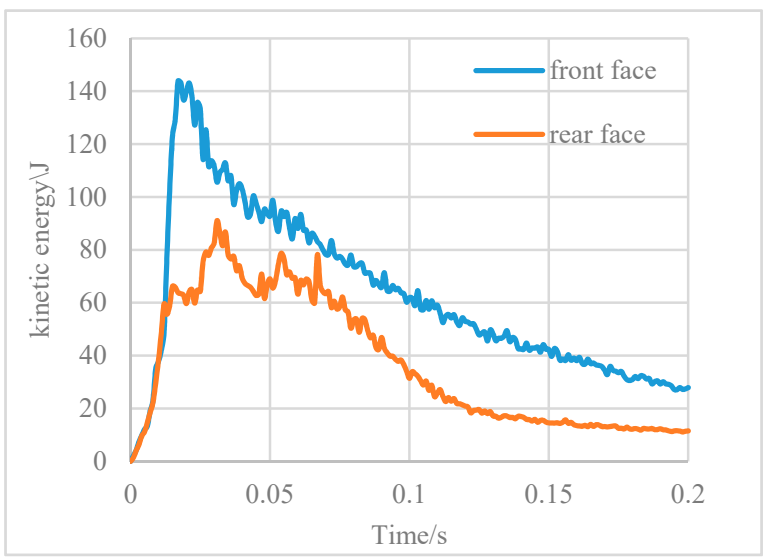

Figure 29. Kinetic energy of the 3-3 wall coating.

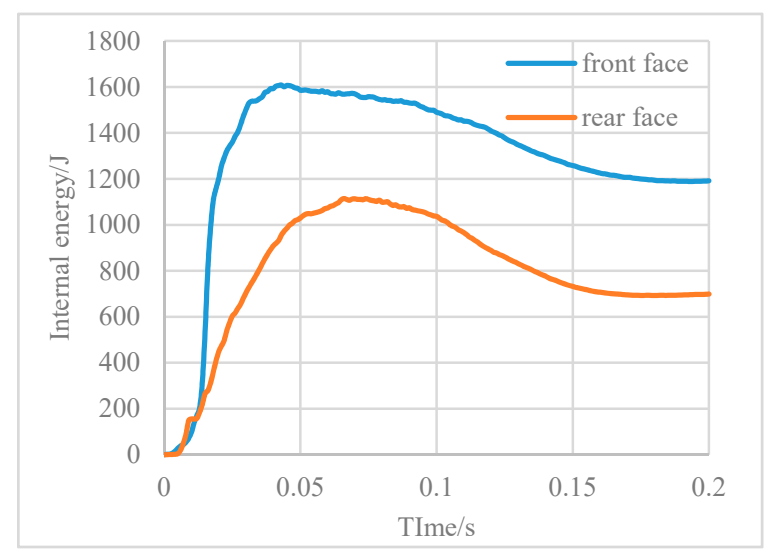

Figure 30. Internal energy of the 3-3 wall coating.

The displacements of the walls strengthened with the same thicknesses are shown in Figure 31. The maximum displacements of the $0-6,3-3$, and $2-4$ walls were $0.21,0.11$, and $0.09 \mathrm{~m}$, respectively. The explosion resistances of the masonry walls could be further improved by optimizing the combination of the coating spraying method and thickness. 


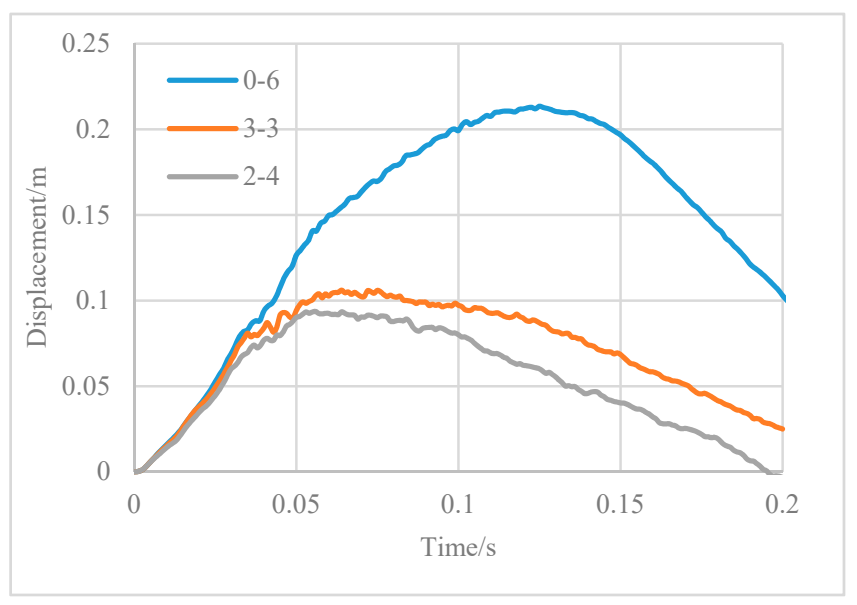

Figure 31. Displacements of walls strengthened with the same thickness.

\section{Conclusions}

In this study, the dynamic impact responses of walls strengthened with polyuria layers were investigated through a series of impact tests under the blast loads generated by gas explosions instead of high explosives. The calibrated numerical model was conducted on parametric studies. The conclusions are summarized as follows:

(1) The wall damage modes under gas explosions were analyzed, the masonry walls experienced bending damage and then collapsed. The presence of the polyurea coatings could effectively improve the anti-explosion abilities of masonry walls, prevent wall collapses, and retain the flying fragments. Excellent reinforcement effect and no influence on normal production make polyurea coating an alternative method to strengthen existing petrochemical buildings.

(2) The bond between the polymer and masonry wall is critical for the reinforcement effectiveness. Premature debonding results in a failure of the coating to exert the maximum energy absorption effect. Spraying operations should be carried out under suitable temperature and humidity conditions to improve the adhesion of the coating. Furthermore, steel angle can also be used to reinforce the coating around the frame.

(3) When polyurea was sprayed only on the front face of a masonry wall, debris was still launched from the back of the wall. The blast-resistant ability of the front polyurea-coated wall was not significantly enhanced, and it was weaker than the rear and double-side polyurea-coated walls.

(4) Compared with the rear polyurea-coated wall, the blast-resistant ability of the double-side polyurea-coated wall improved significantly. Double-sided reinforcement should be used in building reinforcement to improve the wall explosion resistance. Rear-face reinforcement can be selected when construction conditions are limited. In addition, the explosion resistance of masonry walls can be further improved by optimizing the combination of the spray method and coating thickness

Subsequent tests can be carried out to investigate characteristics of wall fragments, proposing an analytical model to accurately predict the debris distribution at low computational cost. Several other parameters can be included in future tests such as elongation, tensile strength, tear strength, and hardness of polyurea coating. The performance criteria for coatings could be optimized to better blast reinforcement.

Author Contributions: Conceptualization, A.Y. and M.G.; methodology, M.G. and X.L.; software, M.G.; formal analysis, G.C.; data curation, X.L.; writing-original draft preparation, M.G.; writing-review and editing, A.Y. and H.W.

Funding: This research received no external funding.

Conflicts of Interest: The authors declare no conflict of interest. 


\section{References}

1. Knox, K.J.; Hammons, M.I.; Lewis, T.T.; Porter, J.R.; Branch, F.P. Polymer Materials for Structural Retrofit, Florida: Force Protection Branch, Air Expeditionary Forces Technology Division; Air Force Research Laboratory, Tyndall AFB: Panama, FL, USA, 2000.

2. Shi, Y.C.; Xiong, W.; Li, Z.X.; Xu, Q.F. Experimental studies on the local damage and fragments of unreinforced masonry walls under close-in explosions. Int. J. Impact. Eng. 2016, 90, 122-131. [CrossRef]

3. Keys, R.A.; Clubley, S.K. Establishing a predictive method for blast induced masonry debris distribution using experimental and numerical methods. Eng. Fail. Anal. 2017, 82, 82-91. [CrossRef]

4. Zapata, B.J.; Weggel, D.C. Collapse Study of an Unreinforced Masonry Bearing Wall Building Subjected to Internal Blast Loading. J. Perform. Constr. Fac. 2008, 22, 92-100. [CrossRef]

5. Solveig, H.; Kristoffer, B.; Petter, I.; Svein, O.C. Global Response of a Three-Story Building Exposed to Blast Loading. Proceedings 2018, 2, 386-392.

6. Wu, C.; Oehlers, D.J.; Rebentrost, M.; Leach, J.; Whittaker, A.S. Blast testing of ultra-high performance fibre and FRP-retrofitted concrete slabs. Eng. Struct. 2009, 31, 2060-2069. [CrossRef]

7. Valluzzi, M.R.; Valdemarca, M.; Modena, C. Behavior of Brick Masonry Vaults Strengthened by FRP Laminates. J. Compos. Constr. 2001, 5, 163-169. [CrossRef]

8. Alsayed, S.H.; Elsanadedy, H.; Al-Zaheri, Z.M.; Al-Salloum, Y.A.; Abbas, H. Blastresponse of GFRP-strengthened infill masonry walls. Constr. Build. Mater. 2016, 115, 438-451. [CrossRef]

9. Elsanadedy, H.; Al-Salloum, Y.; Al-Zaheri, Z.; Alsayed, S.; Abbas, H. Behavior anddesign aspects of FRP-strengthened URM walls under out-of-plane loading. J. Compos. Constr. 2016, 20, 04016048. [CrossRef]

10. Chen, Y.S.; Wang, B.; Zhang, B. Polyurea coating for foamed concrete panel: An efficient way to resist explosion. Def. Technol. 2019. [CrossRef]

11. Mosallam, A.S. Out-of-plane flexural behavior of unreinforced red brick walls strengthened with FRP composites. Compos. Part. B Eng. 2007, 38, 559-574.

12. Buchan, P.; Chen, J. Blast resistance of FRP composites and polymer strength-ened concrete and masonry structure sea state-of-the-art review. Compos. Part B Eng. 2007, 38, 509-522. [CrossRef]

13. Davidson, J.S.; Fisher, J.W.; Hammons, M.I. Failure Mechanisms of Polymer-Reinforced Concrete Masonry Walls Subjected to Blast. J. Struct. Eng. 2005, 131, 1194-1205. [CrossRef]

14. Davidson, J.S.; Porter, J.R.; Dinan, R.J. Explosive Testing of Polymer Retrofit Masonry Walls. J. Perform. Constr. Fac. 2004, 18, 100-106. [CrossRef]

15. Wang, J.G.; Ren, H.; Wu, X.; Cai, C.L. Blast Response of Polymer-Retrofitted Masonry Unit Walls. Compos. Part. B Eng. 2017, 128, 174-181. [CrossRef]

16. Moradi, L.G.; Davidson, J.S.; Dinan, R.J. Response of Bonded Membrane Retrofit Concrete Masonry Walls to Dynamic Pressure. J. Perform. Constr. Fac. 2009, 23, 72-80. [CrossRef]

17. Li, Z.; Chen, L.; Fang, Q. Experimental and numerical study of unreinforced clay brick masonry walls subjected to vented gas explosions. Int. J. Impact. Eng. 2017, 104, 107-126. [CrossRef]

18. Guiqiu, L.; Chuxian, S.; Yibiao, L. Analyses of the elastic modulus values of masonry. J. Hunan Univ. Nat. Sci. 2008, 35, 29-32.

19. Chunyi, X.; Ming, L.; Haiying, Z. Experiment and numerical simulation on axial compressive performance of autoclaved fly ash solid brick masonry columns. Trans. Tianjin Univ. 2011, 17, 454-460.

20. Weizhong, F.; Hao, Y. Research on the compression strength test of common clay brick by rebound measures. Res. Explor. 2013, 31, 35-37.

21. Wang, H.; Deng, X.; Wu, H.; Pi, A.; Li, J.; Huang, F. Investigating the dynamic mechanical behaviors of polyurea through experimentation and modeling. Def. Technol. 2019. [CrossRef]

22. GB50779-2012. Code for Design of Blast Resistant Control Building in Petrochemical Industry; Planning Press: Beijing, China, 2012.

23. Bounds, W.L. (Ed.) Design of Blast Resistant Buildings in Petrochemical Facilities; ASCE: Reston, VI, USA, 2010.

(C) 2019 by the authors. Licensee MDPI, Basel, Switzerland. This article is an open access article distributed under the terms and conditions of the Creative Commons Attribution (CC BY) license (http://creativecommons.org/licenses/by/4.0/). 